\title{
SOCIAL MEDIA MARKETING SEBAGAI SARANA PENGEMBANGAN KEWIRAUSAHAAN BERBASIS SOCIO- TECHNOPRENEURSHIP DI UNIVERSITAS ISLAM RIAU
}

\author{
Benni Handayani ${ }^{1}$, Fatmawati Moekahar ${ }^{2}$, Yudi Daherman ${ }^{3}$, Mufti Hasan Alfani ${ }^{4}$ \\ ${ }^{1234}$ Universitas Islam Riau \\ Email: bennihandayani@comm.uir.ac.id
}

Diterima : 30 Juni 2020

Disetujui : 21 Juli 2020

Diterbitkan : 28 Agustus 2020

\begin{abstract}
Abstrak
Bisnis kreatif dalam beberapa dekade terakhir mengalami perkembangan ditopang dengan kemutakhiran teknologi. Fenomena ini kemudian dikomodifikasi menggunakan pendekatan sosial. Model di atas dikenal dengan istilah Socio-technopreneurship. Penelitian ini membahas mengenai social media marketing sebagai media pemasaran dan media sosial dengan memanfaatkan teknologi dalam membangun brand awareness ke-5 jenis usaha diantaranya unaware of brand, brand recognition, brand recall, dan top of mind, mendukung selebgram, penelitian ini berpusat di business center kantin terapung Universitas Islam Riau yang mengakomodasi berbagai wirausaha muda baik mahasiswa maupun alumni dengan bentuk bisnis di bidang apapun baik barang maupun jasa. Penelitian ini menggunakan pendekatan kualitatif deskriptif, pengumpulan data melalui observasi, wawancara, dan dokumentasi. Kesimpulan didapatkan bahwa kompetensi pengelolaan media sosial khususnya Instagram yang digunakan oleh para informan untuk media bisnis cenderung masih konvensional, padahal trend terbaru dalam dunia bisnis online sudah semakin dinamis dan variatif. Pengembangan Socio-technopreneurship pada akhirnya menjadi sebuah metode yang signifikan sebagai upaya untuk meningkatkan kompetensi di atas.
\end{abstract}

Kata Kunci: Social Media Marketing, Socio-technopreneurship, Brand Awareness

\begin{abstract}
Creative business in the last few decades has experienced growth supported by technological advancements. This phenomenon is then commodified using a social approach. The above model is known as Socio-technopreneurship. This study discusses social media marketing as marketing media and social media by utilizing technology in building brand awareness of the 5 types of businesses including unaware of brand, brand recognition, brand recall, and top of mind, supporting students, this research is centered in the business center floating canteen of the Riau Islamic University that accommodates a variety of young entrepreneurs both students and alumni with forms of business in any field both goods and services. This research uses a descriptive qualitative approach, collecting data through observation, interviews, and documentation. The conclusion was that social media management competencies especially Instagram used by informants for business media tend to be conventional, even though the latest trends in the online business world are increasingly dynamic and varied. The development of Socio-technopreneurship eventually becomes a significant method in an effort to improve the above competencies.
\end{abstract}

Keywords: Social Media Marketing, Socio-technopreneurship, Brand Awareness 


\section{PENDAHULUAN}

Kekayaan alam atau sumber daya alam sebuah negara tidak menjamin kemakmuran dan kesejahteraan secara berkelanjutan bila tidak dikelola oleh kompetensi sumber daya manusia yang baik. Rendahnya inovasi teknologi dan sektor kewirausahaan juga berimbas pada daya saing sebuah negara. Oleh karena itu pengelolaan sumber daya manusia yang benar merupakan salah satu indikator penting. Untuk meningkatkan daya saing terutama kualitas wirausaha, hal ini diperkuat dengan temuan dalam penelitian (Dewi, 2013) bahwa Manajemen Sumber Daya Manusia berpengaruh positif terhadap perkembangan usaha. Sumber Daya Manusia yang cukup potensial untuk menciptakan inovasi dan mempunyai semangat Enterpreneurship adalah anak muda,

Enterpreneurship pada awalnya berkembang dan berasal dari teori Schumpeter pada tahun 1934, dimana Enterpreneurship berarti pengusaha baru yang melaksanakan kombinasi baru dalam bidang Teknik komersial ke dalam bentuk praktik (Hasanah, 2015). Kata Enterpreneurship jika diterjemahkan ke dalam Bahasa Indonesia berarti "kewirausahaan". Kata ini juga berasal dari serapan Bahasa perancis yaitu etrependre yang bila di alihbahasakan ke Indonesia berarti "bertanggung jawab". Wiraswasta/wirausaha berasal dari kata: Wira: utama, gagah berani, luhur; usaha: kegiatan produktif (Hadiyati, 2011). Dari asal kata tersebut, dapat diartikan bahwa seorang wirausaha ditujukan pada orang-orang yang dapat berdiri sendiri, tidak bekerja di sektor pemerintahan, seperti pedagang pengusaha yang memiliki usaha sendiri. Senada dengan (Yaghoobi et al., 2010) mengatakan bahwa wirausahawan adalah orang yang berani menciptakan kegiatan produktif yang sifatnya mandiri.

Progresivitas ilmu kewirausahaan baik diitinjau dari jumlah, kemandirian, kreatifitas dan inovatif, semakin mudah ditemukan dalam kehidupan masyarakat Indonesia saat ini (Abdurrahman, 2015). Bahkan hingga seorang gamer pun bisa memilih orientasi menjadi profesional dan menghasilkan keuntungan finansial di era digital sekarang ini (Riauan \& Aziz, 2019)

Hal ini tentunya menjadi sangat linier dengan kemutakhiran teknologi komunikasi dan informasi, terutama media, yang pada dasarnya tidak lagi tumbuh hanya sebagai alat politik, sosial dan budaya, namun semakin menyatu dengan orientasi ekonomi. Sebuah konsep yang cukup menarik baru-baru ini diperkenalkan oleh beberapa pakar di Indonesia yaitu konsep Socio-Technopreneurship. Socio-Technopreneurship merupakan penggabungan dari tiga kata yaitu Socio/Sosial/Kemasyarakatan, techno/teknologi, dan entrepeneur atau dalam bahasa Indonesia biasa dikenal dengan istilah kewirausahaan. Jadi pada dasarnya dapat diartikan konsep Socio-Technopreneurship merupakan pengembangan wirausaha dengan support teknologi yang memberikan dampak kepada masyarakat. Konsep ini hampir sama dengan Business-preneursip hanya saja capaian Business-preneursip berbicara mengenai keuntungan semata.

Raldi. A. Koester yang dijuluki "bapak bayi tabung" di Indonesia merupakan salah satu tokoh pertama yang sukses mengimplementasikan Socio-technopreneurship temuannya dalam proyek pengembangan inkubator bayi dan lampu photograpy menjadi teknologi tepat guna yang diciptakan dengan cost yang sangat minim, pada akhirnya penyewaanpun menjadi sangat murah sehingga mampu menyentuh pasar masyarakat kurang mampu tanpa perlu lagi 
mengandalkan penyewaan alat inkubator sebelumnya yang pada umumnya berkisar pada harga yang cukup tinggi. Di awal pengujiannya selama 4 tahun, terhitung telah lebih dari seribu bayi dari 14 provinsi di Indonesia telah berhasil bertahan hidup dimasa prematur (Koestoer \& Roihan, 2016).

Konsep Socio-technopreneurship sangat dekat dengan perkembangan perusahaan startup di Indonesia, sebab Socio-technopreneurship merupakan sebuah konsep bisnis pemanfaatan teknologi dan inovasi yang nantinya menjadikan solusi bagi permasalahan masyarakat umum. Dalam arti lain Socio-technopreneurship lebih mengedepankan aktivitas sosial dari pada keuntungan, namun konsep ini masih menjadi perdebatan, seperti menurut (Sukur, 2012) Sosio-Technopreneurship antara teori dan praktek di lapangan, ada hal-hal yang tidak benar dengan kata 'socio', seolah-olah acara tersebut dipentaskan kegiatan sosial. Sebagai hasil dari kegiatan yang dilakukan hanya kegiatan yang bersifat sosial sementara sedikit - sedikit mengangkat unsur teknologi dan kewirausahaan. Faktor utama yang menjadi parameter justru terabaikan, seperti penghasilan. Pada akhirnya keuntungan yang dihasilkan dihitung sangat sederhana, yaitu, penjualan berkurang. Dalam melakukan produksi dan bisnis kegiatan harus dihitung penyusutan aset, biaya operasi, manajemen penggajian dan itu semua harus selalu dirilis pada setiap bulan.

Menyusutnya penjualan merupakan salah satu indikasi aspek sosial tidak dikedepankan dalam komunikasi pemasaran terpadu, padahal dalam komunikasi pemasaran terpadu (integrated marketing communication) dijelaskan bahwa pengelolaan hubungan dengan konsumen yang intinya untuk meningkatkan brand value merupakan aspek terpenting. Hal ini yang kerap terabaikan oleh pebisnis pemula. Salah satu tools untuk meningkatkan indikator brand value adalah dengan memaksimalkan penggunaan media sosial. Hal ini seperti penjelasan (Morissan, 2010) bahwa tujuan memilih bisnis menggunakan fsilitas e-commerce sebagai pemasaran yaitu:

1. Menjangkau lebih luas target konsumen

2. Bersifat duarah dengan biaya yang relatif murah

3. Mampu langsung menjangkau segmentasi pasar yang ingin dituju

4. Mudah dalam menyampaikan perubahan informasi produk

5. Tidak terbatas akses.

6. Biaya iklan yang lebih murah dan efektif

7. Mampu menjadi saluran alternatif

Fakta membuktikan bahwa digital marketing dapat menjangkau semua kalangan, melalui cara apapun dan bisa dilakukan kapan saja dimana saja, hal ini jelas lebih mengungguli marketing cara konvensional yang terbatas dari berbagai aspek. Hal ini dibuktikan oleh penelitian dari Putri dan Fitrah (2017) bahwa terdapat pengaruh yang sangat signifikan terhadap kampanye online marketing dengan kebiasaan calon konsumen dalam menentukan pilihan barang atau jasa yang ingin digunakan. Faktor utama dari fenomena ini adalah karena media sosial yang dewasa ini sedang menjadi trend hampir diseluruh kalangan masyarakat di Indonesia disebabkan oleh menjamurnya penggunaan telepon seluler dan fitur-fitur yang semakin memudahkan. Proses penyebaran informasi semakin terbuka lebar, apalagi jika kita berbicara mengenai memasarkan sebuah produk maka digital marketing terutama yang berbasis dengan social media dengan mudahnya memberikan akses apapun 
mengenai produk yang akan di tawarkan, konsumen lebih dimanjakan dengan penghematan ruang dan waktu, tanpa perlu melihat produk di toko, atau mendatangi secara langsung sebelum memutuskan untuk membeli (Oktaviani \& Rustandi, 2018). Sayangnya tidak semua pemilik produk mengaktualisasikan teknik marketing sesuai dengan perkembangan zaman. Masih banyak dari mereka ya g mengalami beberapa kendala terhadap teknis dalam melakukan social media marketing.

Rendahnya kemampuan pebisnis pemula dalam transaksi online menjadi perhatian banyak kalangan, sebab keberhasilan bisnis ditentukan juga dengan seberapa konsisten bisnis tersebut terhubung dengan internet dalam membangun jaringannya (Sahban, 2018). Faktor kedua adalah kemampuan mengenai konsep komunikasi bisnis, menurut Pride, et al., (2014) komunikasi bisnis merupakan kegiatan dan usaha individu yang terorganisir dalam rangka menghasilkan dan menjual barang/jasa untuk mendapat keuntungan dan memenuhi kebutuhan masyarakat. Berdasarkan pengertian di atas terlihat jelas bahwa keuntungan serta pemenuhan kebutuhan masyarakat adalah suatu hal yang harus dinarasikan untuk saling bertautan, di sinilah skill komunikasi bisnis dibutuhkan Hal ini yang masih kerap menjadi kendala beberapa pebisnis pemula.

Beberapa kendala lain yang dialami oleh pebisnis pemula juga dijelaskan dalam penelitian (Rosyadi, 2013) usaha mikro dan kecil milik mahasiswa cenderung bersifat historically transmitted, pada akhirnya menghambat perkembangan usaha pada beberapa kasus. Kemudian skill kewirausahaan yang relatif masih rendah juga menjadi faktor perkembangan tersebut terhambat. Untuk itu diperlukan upaya peningkatan skill dalam merambah pasar melalui social media marketing. Lebih jelas lagi, Constantinides menyatakan bahwa social media marketing dapat diklasifikasikan jenis aplikasi social media, kesesuaian antara aktifitas social media marketing dan tujuan marketing. Perusahaan atau enterpreneur memiliki dua pendekatan utama untuk aktivitas social media mereka sebagai bagian dari strategi marketing yaitu pasif dan aktif. Pendekatan pasif seperti listening-in atau mendengarkan, menyiratkan penggunaan aplikasi social media sebagai sumber suara pelanggan dan informasi pasar. Disisi lain untuk pendekatan aktif, berkaitan dengan penggunaan aplikasi social media untuk tujuan marketing seperti berikut ini:

1. Sebagai alat public relations dan direct marketing.

2. Melibatkan kepribadian sebagai sarana untuk mempengaruhi pelanggan dan sebagai pendukung produk/merek.

3. Menyesuaikan pengalaman online pelanggan dan memungkinkan penyesuaian produk.

4. Melibatkan pelanggan dalam proses kreasi dan inovasi, serta dalam ulasan produk atau konsep periklanan. (Constantinides, 2013)

Perusahaan menentukan taktik social media marketing mereka mengikuti keputusan dan rencana tersebut di pasar sasaran (target market), bauran pemasaran (marketing mix), dan tujuan marketing. Dalam konteks ini, taktik social media marketing adalah aktivitas yang terkait dengan tujuan jaringan dari konteks campuran media sosial misalnya. aktivitas yang memfasilitasi percakapan tentang merek atau perusahaan, dan menghubungkan perusahaan dengan audiens mereka. Jadi, taktik social media marketing mencakup pilihan aplikasi atau alat media sosial, kemudian setelah perencanaan dan keputusan, perusahaan dapat 
melakukan tindakan strategis mereka di media sosial yang mereka pilih. Ada tiga kategori utama tindakan social media marketing: representasi, engagement, dan mendengarkan (listening-in).

a) Representasi mencakup aktivitas media sosial yang berfokus pada penyampaian komunikasi pemasaran terkait profil perusahaan dan informasi tentang produk.

b) Engagement, atau proposisi nilai tambah, mencakup aktivitas pemasaran yang berfokus pada interaksi dengan pelanggan, menambah nilai bagi mereka dan menghasilkan manfaat bagi perusahaan: manajemen hubungan pelanggan, pemasaran satu-ke-satu, pemberdayaan pelanggan, dukungan pelanggan, personalisasi informasi, kustomisasi produk, atau program loyalitas pelanggan (Müller, et al., 2006). Dalam kasus B2B, keterlibatan perusahaan mencakup hubungan di sepanjang rantai pasokan - pemasok, pengecer, dan mitra bisnis (Jussila et al., 2014; Rapp, et al., 2013).

c) Aktivitas mendengarkan (listening-in) memungkinkan cara pasif keterlibatan media sosial yang bertujuan untuk riset pasar dan intelijen, seperti analitik konten dan percakapan media sosial - berbagi suara, sentimen, celah, tren, peluang, dll. - serta identifikasi faktor dan pemberi pengaruh yang relevan.

Dalam perkembangannya social media marketing paling banyak digunakan untuk berbisnis baik barang maupun jasa. Sejak awal peluncurannya pada tahun 2010 sebelum diakuisisi oleh facebook pada tahun 2012, Instagram terdiri dari 2 kata yaitu 'insta' atau 'instant' dan 'gram' yang berasal dari 'telegram'. Jadi Instagram bisa di maknai layanan membagikan foto dan video secara cepat dan praktis (Hanggono, 2015). Namun karena pembaharuan yang dinamis hingga saat ini menempatkan Instagram sebagai media sosial paling banyak digunakan untuk bisnis. Instagram menjadi sangat fenomenal ditandai sejak 2016 Instagram melengkapi fiturnya seperti pendahulu nya yaitu Snapchat berupa ephemeral konten. Menurut digital marketing institute, konten ephemeral adalah model konten di media sosial berupa foto atau video yang diunggah dan berbatas waktu (singkat) atau temporari, umumnya hanya tersedia dalam 24 jam, salah satu contohnya adalah Instastory (Villaespesa $\&$ Wowkowych, 2020). Konten ini semakin digandrungi karena senada dengan kebiasaan pengguna smartphone untuk terus menatap layar gadgetnya setiap waktu. Karena sifatnya temporal, biasanya pengguna tidak ingin melewatkan momen-momen yang muncul di akunnya (Bayer, et al., 2016). Untuk pengguna akun bisnis Instagram tentunya konten ephermal tidak membutuhkan anggaran yang besar dan perencanaannya cenderung biasa saja namun hasilnya sangat efektif, tergantung seberapa menarik anda berkreasi.

Menurut artikel (Nuraeni \& Suryawardani, 2017) menunjukan bahwa Instagram merupakan sarana promosi yang paling efektif, persentase yang didapat bahkan hingga $66 \%$ dibandingkan dengan menggunakan media sosial lainnya. Begitu pula dengan penelitian yang dilakukan oleh (Diyatma \& Irma, 2017) bahwa keputusan membeli produk sebesar $83,44 \%$ dipengaruhi oleh media sosial Instagram. Secara garis besar terbukti bahwa Instagram memberikan peluang yang sangat potensial kepada para pelaku usaha terutama pemula untuk mempromosikan produknya dan memperoleh omset yang sangat signifikan walau dengan biaya markteing yang kecil (Dewi, 2018). 
Hal ini merefleksikan asumsi dasar dari teori new media bahwa semua orang saat ini dapat langsung menaruh dan mengambil peran apapun di dalam internet (Littlejohn \& Karen, 2009).

1. Sedikitnya ada tiga kategori utama studi tentang social media dalam kegiatan bisnis dan marketing, yaitu; 1. Sikap dan prilaku konsumen terhadap social media marketing;

2. Adopsi dan penggunaan social media marketing, Kategori ini berputar di sekitar perspektif manajerial, eksekutif atau pengambilan keputusan, serta persepsi perusahaan tentang penggunaan social media marketing di peganisasi mereka. Selain itu kateogi ini mencakup tentang mendorong atau memotivasi perusahaan untuk menerapkan social media marketing. Lorenzo-Romero, et al (2013) menjelaskan bahwa alasan utama penggunaan media sosial untuk sebagian besar pengecer kecil adalah kegunaan media sosial yang dirasakan untuk layanan pelanggan dan jaringan, sedangkan untuk pengecer menengah alasan utamanya adalah untuk menyediakan layanan pelanggan dan membangun merek, dan tujuan perusahaan besar untuk membangun merek. Tsimonis dan Dimitriadis (2014) mengungkapkan bahwa motivasi yang paling sering mengarahkan merek untuk terlibat di media sosial adalah pertumbuhan, popularitas dan sifat viral dari media sosial, kehadiran pesaing di media sosial, dan tekanan untuk menekan biaya;

3. Dampak social media marketing pada penjualan dan kinerja keuangan (Kumar, et al., 2013).

Dalam membangun sebuah merek, diperlukan kemampuan untuk membangun brand awareness. brand awareness merupakan kemampuan merk sebuah produk dalam hal menyodorkan daya tarik sehingga mudah diingat oleh konsumen (Guzmán, et al., 2009). Peran brand awareness dalam keseluruhan tergantung oleh sedalam mana tingkatan kesadaraan yang telah dicapai oleh sebuah merek, menurut Rangkuti (2002) terdapat 5 tahapan brand awareness yaitu;

- Brand Unaware; Adalah keadaan dimana konsumen belum mengenal brand, dalam tingkatan ini jelas bahwa brand awareness belum terbangun.

- Brand Recognition; Merupakan tingkatan minimal dalam hal kesadaran sebuah merek, artinya pengenalan suatu merek akan kembali muncul jika disadarkan atau berupa pengingatan kembali dengan stimulus tertentu.

- Brand Recall; merupakan pengulangan ingatan terhadap suatu merek didasarkan pada permintaan penyebutan kelas produk tertentu

- Top of Mind; merupakan merek yang paling pertama teringat dan tersebutkan oleh konsumen, artinya merek terebut telah dianggap merek utama sebuah produk oleh konsumen.

Pengelolaan yang tepat terhadap sebuah merek tentunya menjadi hal yang akan menyokong identitas merek itu sendiri. Kesadaran akan suatu merek merupakan tantangan awal untuk pemilik merek baru atau bahkan merek lama dalam mempertahankan tingkatan kesadarannya (Setiawan, 2017). Berikut ini adalah gambar tingkatan piramida kesadaran merek (brand awareness). 
Gambar 1: Piramida Kesadaran Merek

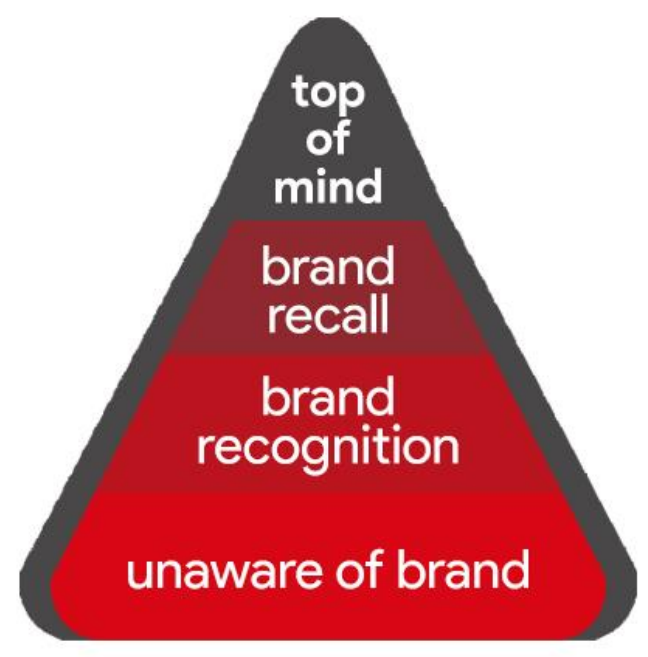

Hal yang menjadi pembaharuan dalam penelitian ini adalah bagaimana konsep Sociotechnopreneurship dalam perspektif media sosial ini akan diamati dari penggunaan aplikasi media sosial sebagai treathment interaksi yang saling menguntungkan kepada pemilik usaha dan pelanggan. Artinya perlunya meningkatkan keuntungan finansial melalui pendekatan sosial ditopang dengan memaksimalkan teknologi media sosial. Berdasarkan uraian diatas maka peneliti berusaha menganalisa secara komperhensif dan mendalam, untuk melihat sejauh mana media sosial telah dimanfaatkan oleh pebisnis pemula dengan basis sociotechnopreneurship dalam membangun brand awareness.

\section{METODOLOGI PENELITIAN}

Peneliti menggunakan pendekatan kualitatif dengan tipe deskriptif. Artinya prosedur pengungkapan data dan fakta yang peneliti gunakan adalah dengan bentuk non statistik atau non sistematis. Metode kualitatif mempunyai prosedur pengamatan perilaku serta dideskripsikan secara tulisan ataupun lisan, prosesnya melalui pengumpulan, analisis dan interpretasi data kemudian ditutup dengan penarikan kesimpulan berdasarkan analisis data tersebut (Moleong, 2007).

Peneliti membatasi 5 jenis usaha (tenant) dengan menggunakan Teknik purposive sampling yaitu Teknik pemilihan informan yang akan diteliti dengan menggunakan kriteria/pertimbangan khusus dari peneliti. Ke-5 tenant ini adalah;

a. HR Makaroni, (Informan I) merupakan jenis usaha kuliner jajanan kering, berbentuk cemilan makaroni dengan pengolahan digoreng,

b. Etahu.ga, (Informan II) merupakan jenis usaha kuliner berbentuk cemilan pedas berbahan dasar tahu dengan beberapa varian berisi bakso dan lainnya,

c. Hijab PKU Amanah (Informan III) merupakan jenis usaha jilbab wanita,

d. Stick Mozarella PKU, (Informan IV) merupakan jenis usaha kuliner berbentuk cemilan memiliki kekhasan mozzarella,

e. Shoes Homies, (Informan V) merupakan jenis usaha jasa laundry sepatu. 
Seperti yang disebutkan oleh (Chaedar, 2002) bahwa objek penelitian adalah mencakup permasalahan yang akan diteliti. Maka dalam penelitian ini objek penelitiannya yaitu pemanfaatan Instagram sebagai social media marketing dalam membangun brand awareness oleh ke-5 tenant tersebut. Lokasi penelitian berpusat di kota Pekanbaru tepatnya di Universitas Islam Riau, kemudian pengumpulan data dilakukan dengan 3 teknik seperti yang ditulis oleh (Bungin, 2008) 1; wawancara, melakukan proses tanya jawab baik direct maupun indirect, 2; melakukan observasi dengan mengamati serta mencatat peristiwa secara langsung, 3; melakukan dokumentasi baik doumen maupun rekaman.

\section{HASIL DAN PEMBAHASAN}

Menurut Singh (2010) dalam jurnal (As'ad et al., 2014) menyatakan bahwa di dalam social media marketing terdapat sharing of content yang digunakan sebagai media pertukaran informasi, mendistribusi, dan mendapatkan konten melalui social media. Sehingga dengan adanya pemanfaatan media sosial Instagram sebagai social media marketing dalam sebuah bisnis dinilai sangat efisien dan efektif untuk memperkenalkan sebuah produk brand kepada masyarakat luas maupun konsumen. Adanya accessibility social media tentu memberikan kemudahan bagi para pengguna untuk melakukan akses, karena tidak memerlukan keterampilan atau pengetahuan tertentu dalam menggunakan maupun mengakses situs tersebut, hal ini bersamaan dengan biaya yang relatif murah bahkan tanpa mengeluarkan biaya (Taprial \& Kanwar, 2012). Kemudian berkaitan dengan penjelasan oleh (Gunelius, 2011) untuk membangun merek yakni harus tersedianya percakapan melalui media sosial untuk meningkatkan brand awareness, meningkatkan pengenalan, ingatan, serta loyalitas merek. Di bawah ini merupakan hasil dari wawancara ke-5 tenant dalam membangun brand awareness, mulai dari tahap unaware of brand, brand recognition, brand recall dan top of mind.

\section{Mengatasi unaware of Brand melalui Social Media Marketing Instagram}

Salah satu aplikasi media sosial yang paling fleksibel dan sangat dikenal serta hampir dimiliki oleh setiap orang adalah Instargam, Instagram juga kerap dijadikan sebagai alat promosi bisnis online. Berdasarkan hasil observasi dan wawancara dengan Informan, yaitu masing-masing dari HR Makaroni, Etahu.ga, Hijab PKU Amanah, Stick Mozarella PKU, dan Shoes Homies, maka beberapa cara untuk meningkatkan pengetahuan konsumen yang tidak menyadari adanya brand baru (unaware of brand) adalah:

1. Informan I melakukan paid promote yang merupakan sebuah promosi berbayar di media social terutama Instagram, berfungsi untuk menambahkan followers pada akun Instagram dan juga untuk meningkatkan pengetahuan target konsumen terhadap jajanan HR Makaroni. Paid promote dilakukan oleh akun Instagram online shop yang cukup dikenal dan memiliki followers dalam jumlah banyak. Harga untuk sebuah paid promote bervariasi, terkadang diukur dari seberapa banyak jumlah followers di akun yang menawarkan jasa paid promote tersebut. Biasanya, harga paid promote untuk per satu postingan berkisar dari Rp.20.000 - Rp.250.000. Semakin banyak jumlah followers pada akun yang menawarkan paid promote tersebut, maka akan semakin mahal pula harga 
untuk satu kali post. Kemudian juga ditetapkan syarat dan ketentuan yang telah disepakati oleh kedua belah pihak.

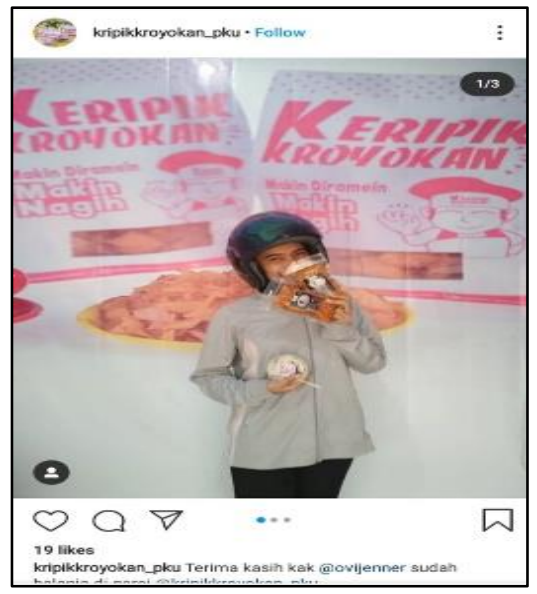

Gambar 2: Paid promote HR Makaroni di salah satu akun online shop.

Informan IV juga memilih beriklan di paid promote pada akun Instagram yang sifatnya publik seperti akun@kulinerpku (meskipun belum pernah mencoba). Informan IV berpendapat bahwa followers akun tersebut memang bertujuan untuk mencari info kuliner di sekitaran kota Pekanbaru, sehingga beriklan di sana dirasa merupakan langkah yang tepat dari pada harus menggunakan jasa endorsement selebgram yang notabene hanya di isi dengan followers fans fanatiknya saja. Sehingga efeknya tidak begitu dirasakan oleh kita yang beriklan.

2. Menggunakan endorsement selebgram, merupakan sebuah promosi berbayar, hampir sama seperti paid promote, namun endorsement ini dilakukan oleh pengguna Instagram yang terkenal dengan jumlah followers yang banyak seperti artis, influencer maupun selebgram. Hal ini belum diterapkan oleh informan I, II, III, IV, V dan 5. Namun Informan II yang merupakan owner dari Etahu.ga berpendapat bahwa lebih memilih menggunakan jasa selebgram / influencer dari pada paid promote menggunakan akun Instagram yang sifatnya publik. Sebab bagi Informan II, selebgram selalu dicitrakan positif oleh followers nya, sehingga apapun yang di pakai, dan di konsumsi selalu akan terlihat bagus dan enak bagi followers nya. Sedangkan menggunakan jasa akun publik, masih terkesan model beriklan yang konvensional.

3. Mengupload foto-foto produk beserta keterangannya kemudian memberikan hashtag berupa (\#) nama produk, (\#) nama bisnis serta hashtag-hashtag lainnya yang bisa untuk mempermudah pencarian akun bisnis tersebut di Instagram, hal ini telah dilakukan oleh informan 1, 3, 4 dan 5, namun tidak diterapkan oleh akun Instagram informan 2, karena bagi Informan 2 hastag tidak begitu signifikan sebab logaritma Instagram yang telah mengarah pada konsistensi dan kerapian tampilan (feed) Instagram, hal ini akan membuat produk anda lebih sering muncul, dari pada sekedar menggunakakn hastag. Pada akhirnya hastag hanya berfungsi manual sebagai keyword untuk pencarian. 

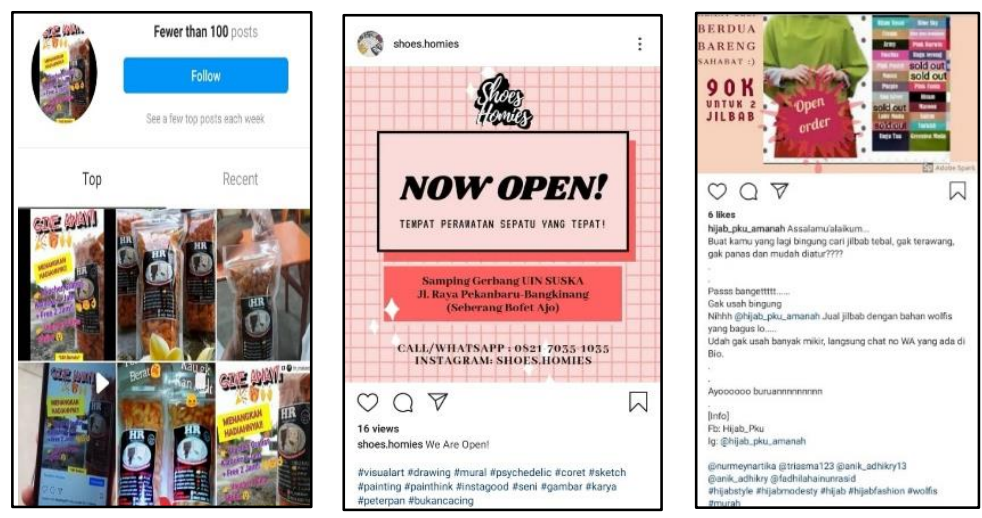

Gambar 3: Penggunaan Hastag (\#) Pada Akun Instagram Bisnis Informan Penelitian.

Dari hasil wawancara dengan seluruh informan tidak satupun menggunakan fitur terbaru dalam aplikasi Instagram, dimana pengguna diberikan opsi untuk beralih ke mode bisnis, kemudian tautan dikoneksikan menuju akun Facebook, untuk mengelola beriklan di Instagram melalui Facebook ads manager. Metode ini sudah mulai digunakan oleh beberapa pebisnis online karena lebih efisien budget, dan mampu menjangkau target konsumen yang kita inginkan, sebab di dalam pengelolaannya pemilik akun bisa memilih target audience mulai dari usia, gender, dan ketertarikan, pada akhirnya pihak Instagram akan memunculkan iklan produk kita seacara otomatis kepada target audience yang muncul pada setiap akun yang masuk dalam kategori pilihan kita sebelumnya, tanpa perlu proses following dan hastag serta menggunakan jasa akun pihak ke-3 (paid promote dan selebgram).

\section{Meningkatkan Pengenalan Brand (Brand Recognition) pada Konsumen}

Tujuan penggunaan media sosial salah satunya membangun merek. Media sosial merupakan langkah yang tepat untuk meningkatkan brand awareness, baik dalam hal pengenalan dan ingatan akan merek serta meningkatkan loyalitas merek.

salah satu cara dalam membangun merek, yaitu dengan mengoptimalkan percakapan melalui media sosial di akun yang kita miliki, sehingga fungsi akun bersifat dua arah dan interaktif. Agar loyalitas terhadap merek kita semakin meningkat. Berikut adalah hasil temuan dari ke-5 tenant yang diwawancarai berkaitan mengenai cara mereka dalam meningkatkan brand recognition.

1. Informan I telah melakukan bentuk brand recognition berupa potongan harga, informasi produk, manfaat dan nilai gizi produk serta mem posting testimonial dari konsumen. Begitu pula hal yang sama dilakukan oleh informan III, dan V.

2. Informan II mengaku belum pernah melakukan tahapan brand recognition di media sosial, dikarenakan produknya sudah dirasa cukup dikenal sebab memiliki lokasi store pada pusat tongkrongan anak muda pada 3 titik selain di pusat bisnis Universitas Islam Riau di kota Pekanbaru, yaitu, di Jalan Delima, Jalan Sail, serta Bundaran Keris Pekanbaru. Bagi Informan II hal ini sudah cukup mengakomodasi tanpa perlu terlalu menghabiskan effort di ranah media sosial. 
3. Informan $\mathrm{V}$ mengaku melakukan bentuk testimoni, serta potongan harga pada momenmomen besar seperti tahun baru, hari raya Idul Adha dan Idul Fitri.
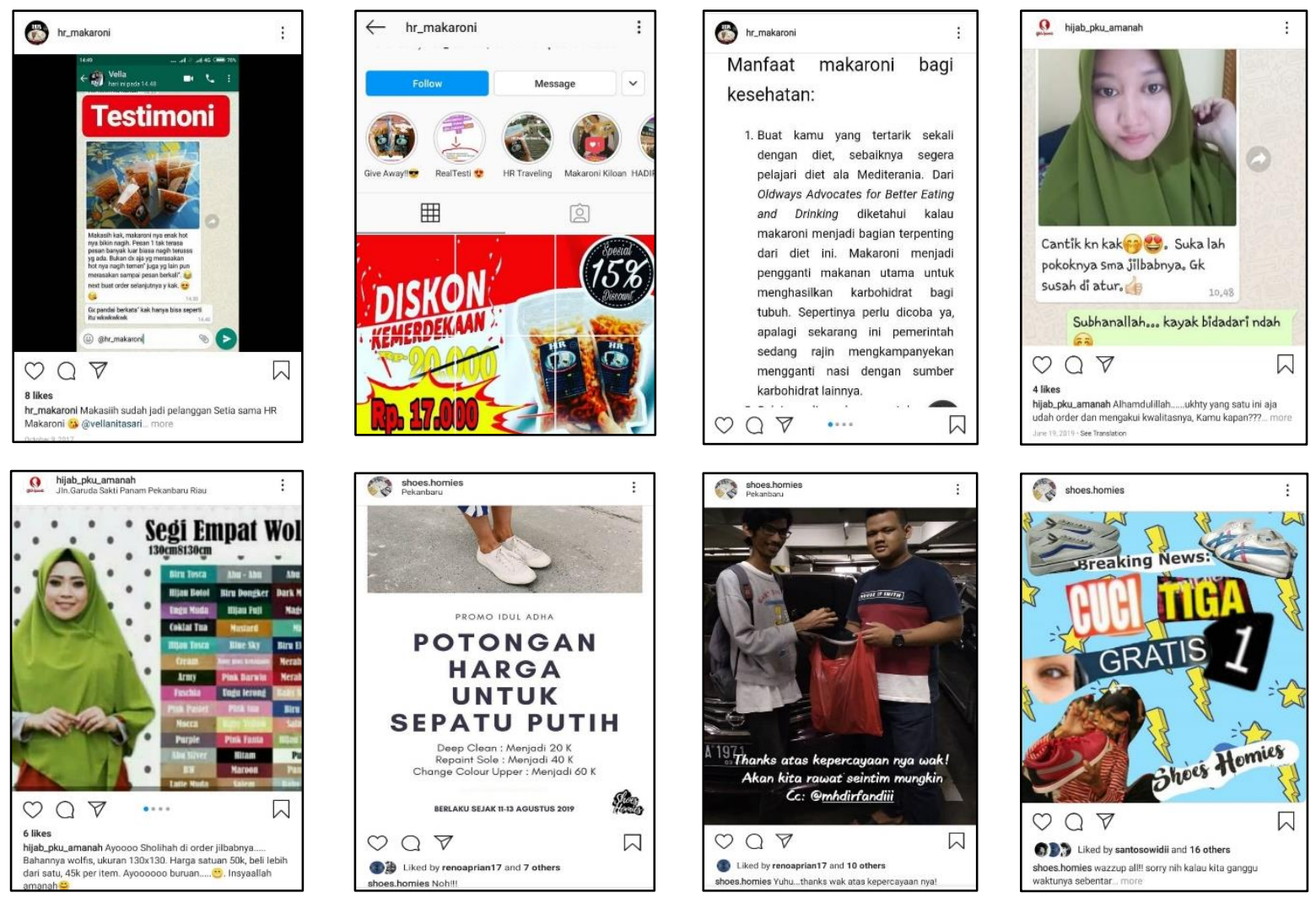

Gambar 4: Potongan Harga, Informasi Produk, dan Testimonial dalam Instagram Informan I, III dan IV

Pada tahapan ini ke-5 tenant mempunyai faktor tertentu untuk mencapai tahapan brand recognition. Namun ada beberapa model yang belum digunakan oleh ke-5 tenant tersebut, yaitu model shareable content. shareable content merupakan model postingan yang dibuat berisikan hal hal yang bermanfaat dan bernilai edukasi bagi audiens, atau hal apapun (tidak harus berkaitan produk anda) yang bila seorang audience melihat, maka seketika langsung meneruskan postingan tersebut dengan melakukan tag kepada nama beberapa orang terdekatnya di kolom komentar.

\section{Meningkatkan Brand Recall melalui Social Media Marketing Instagram}

Brand recall merupakan pengingatan kembali sebuah brand oleh konsumen yang dimana ingatan tersebut tercermin dalam brand lain setelah konsumen menyebutkan brand yang pertama kali (Kotler \& Keller, 2011). Untuk mencapai kesadaran merek maka diperlukan pengenalan serta kemampuan pengingatan merek yang melibatkan berbagai upaya untuk mendapatkan identitas nama kemudian menyambungkannya ke dalam suatu kategori produk. Menurut (Durianto, 2001) salah satu cara agar brand awareness bisa tercapai dan diperbaiki yaitu bisa dengan melakukan pengulangan agar ingatan yang terbentuk lebih kuat di dalam benak konsumen. Oleh karena itu informan I, II, III, IV, dan V 
juga memiliki strategi dalam melakukan pengulangan untuk meningkatkan pengingatan konsumen mereka.

Berdasarkan hasil observasi dan wawancara dengan beberapa informan pada penelitian ini, maka cara untuk melakukan brand recall kepada konsumen adalah dengan cara memberikan informasi seputar produk, atau dengan cara memberikan give away. Contoh beberapa akun menggunakan model give away yaitu berupa metode bagi-bagi hadiah dengan syarat dan ketentuan berlaku, seperti like salah satu postingan dan tag ke beberapa orang teman. Kemudian pemenang dipilih secara acak. Cara lainnya adalah dengan memberikan give away foto voucher gosok paket data internet dengan menutup 1 atau 2 angka terakhir, untuk kemudian dicoba oleh siapa saja followers yang melihat, hal ini lebih bersifat menghibur dan membuat perhatian konsumen kepada akun dan produk kita semakin bertambah. Dengan begitu hasil yang akan didapatkan oleh pemilik bisnis pun sangatlah besar, konsumen akan selalu mengingat brand sehingga tentunya bisa untuk meningkatkan hasil penjualan serta followers dari akun produk kita.

Informan I, II, III, IV dan V mengaku sudah pernah melakukan beberapa strategi brand recall dan dirasa sudah cukup efektif serta efisien dalam melakukan social media marketing. Namun konsistensi dalam melakukan postingan masih kurang dijaga oleh mereka. Kita tau bahwa logaritma dari Instagram lebih mengedepankan intensitas upload. Semakin konsisten dan sering sebuah akun mengunggah produknya maka semakin besar kemungkinan followers akan melihat produk kita di beranda mereka.

Selain itu strategi yang bisa digunakan untuk melakukan brand recall bisa dengan intens membuat kegiatan-kegiatan charity atau program amal, dan beberapa program yang sifatnya insidentil seperti bantuan untuk beberapa korban bencana alam. Hal ini tidak hanya memberikan efek terhadap brand recall namun juga menimbulkan trush pada audiens.

\section{Meningkatkan Puncak Pikiran (top of mind) Konsumen}

Top of Mind (puncak pikiran), merupakan pimpinan dari berbagai merek yang ada dalam pikiran konsumen yang menggambarkan merek yang pertama kali diingat responden atau pertama kali disebut ketika seseorang ditanya tentang suatu kategori produk secara spontan dan tanpa bantuan (Najib, 2009). Selain itu top of mind juga mencerminkan kekuatan dari merek tertentu di dalam benak konsumen berdasarkan kategori produk tertentu. Seperti pasta gigi pepsodent dalam artikel (Sudomo, 2013) menunjukkan hasil bahwa pepsodent menjadi top brand selama 3 tahun berturut-turut dengan top of brand index mencapai $70 \%$ hal ini berdasarkan hasil analisis salah satunya variabel mind of share, semakin nilai mind of share merek tersebut tinggi maka akan semakin kuat pula merek tersebut.

Selain itu, salah satu dimensi social media marketing adalah dimensi credibility, ini terkait bagaimana sebuah perusahaan harus mampu untuk membuat serta menyampaikan pesan dengan jelas kepada konsumen, membangun hubungan emosional yang mampu memotivasi untuk terjadinya pembelian serta mendorong terbangunnya loyalitas pada konsumen. Agar brand awareness dapat terbangun, maka salah satu cara yang bisa dilakukan yaitu dengan membuat pesan yang berbeda dan mudah untuk diingat, serta harus mempunyai hubungan antara merek dengan kategori produknya (Handayani, 2010). 
Oleh karena itu, produk HR Makaroni, Etahu.ga, Hijab PKU Amanah, Stick Mozarella $P K U$, dan Shoes Homies harus memiliki keunikan atau ciri khas tersendiri untuk membedakannya dengan kompetitor lain yang ada di kota Pekanbaru. Untuk mencapai top of mind. Seperti misalnya pada brand HR Makaroni mengaku memiliki keunikan macaroni dengan olahan di goreng. Kemudian produk Etahu.ga memiliki keunikan dari sisi packaging dan komposisi isian tahu yang maksimal. Selanjutnya Hijab PKU Amanah mengaku menjual produk jilbab berbahan premium dengan harga miring, sementara Stick Mozarella PKU mengaku memiliki resep rahasia yang diciptakan sendiri khusus untuk isian toping ayam suir, dan hingga saat proses wawancara berlangsung informan IV memastikan hanya di Stick Mozarella PKU yang memiliki menu isian toping ayam suir. Informan IV pun mengaku bahwa semaksimal mungkin dalam menciptakan keunikan dari desain gerobak, baginya display/tempat berjualan harus semenarik mungkin untuk mengundang konsumen mampir. Sedangkan Shoes Homies memiliki keunggulan dari sisi laundry sepatu, sebab bisnis ini belum terlalu banyak di pekanbaru, dengan kompetitor yang tidak masif ini, informan $\mathrm{V}$ mengaku tidak terlalu menonjolkan keunikan produk pada akun sosial media miliknya, hanya berfokus dengan pelayanan yang maksimal dengan menampilkan testimoni dan hasil pengerjaan.

Pemanfaatan Instagram ternyata sangat membantu HR Makaroni, Etahu.ga, Hijab PKU Amanah, Stick Mozarella PKU, dan Shoes Homies dalam melakukan proses promosi untuk membangun brand awareness masyarakat terkhusus di kota Pekanbaru. Terbukti dari bertambahnya followers dalam kurun dua tahun ini bertambah $20-30 \%$ dan telah memiliki cukup banyak testimoni yang ditampilkan berupa postingan sejak awal dibuatnya media sosial Instagram oleh masing-masing informan.

\section{PENUTUP}

Produk HR Makaroni, Etahu.ga, Hijab PKU Amanah, Stick Mozarella PKU, dan Shoes Homies telah mulai membenahi dan mempelajari dengan seksama cara pengembangan usahanya melalui media sosial. Pertama, dalam upaya untuk meningkatkan pengetahun konsumen yang tidak menyadari adanya sebuah brand (Unaware of Brand) tersebut, maka pelaku bisnis HR Makaroni, Etahu.ga, Hijab PKU Amanah, Stick Mozarella PKU, dan Shoes Homies melakukan kegiata paid promote, endorsement selebgram, serta mengupload foto-foto produk yang dilakukan oleh owner dengan memberikan hashtag untuk mempermudah pencarian akun bisnis tersebut di Instagram. Kedua, pada tahap brand recognition (pengenalan brand), para pelaku bisnis HR Makaroni, Etahu.ga, Hijab PKU Amanah, Stick Mozarella PKU, dan Shoes Homies akan melakukan strategi-strategi pengenalan brand, dimulai dengan intens memberikan promo-promo diskon pada momenmomen hari besar, informasi produk, manfaat dan nilai gizi produk serta mem posting testimonial dari konsumen. Ketiga, pada tahap brand recall kepada konsumennya, para pelaku bisnis HR Makaroni, Etahu.ga, Hijab PKU Amanah, Stick Mozarella PKU, dan Shoes Homies memberikan informasi seputar produk dan memberikan kuis-kuis berhadiah atau giveaway kepada konsumen. Selain itu, dengan intensnya memposting foto-foto produk A B C D setiap harinya. Dengan begitu hasil yang akan di dapatkan oleh HR Makaroni, Etahu.ga, Hijab PKU Amanah, Stick Mozarella PKU, dan Shoes Homies pun sangatlah 
besar, konsumen akan selalu mengingat produk brand HR Makaroni, Etahu.ga, Hijab PKU Amanah, Stick Mozarella PKU, dan Shoes Homies sehingga tentunya bisa untuk meningkatkan hasil penjualan serta followers dari akun merka masing-masing. Keempat, upaya dalam meningkatkan top of mind pada konsumen itu tidaklah mudah. Namun, $H R$ Makaroni, Etahu.ga, Hijab PKU Amanah, Stick Mozarella PKU, dan Shoes Homies selalu berusaha untuk terus meningkatkan top of mind dibenak para konsumennya dengan memanfaatkan Instagram sebagai social media marketing untuk menonjolkan keunikan produk mereka masing-masing. Hal tersebut dapat dilihat dari bertambahnya followers $H R$ Makaroni, Etahu.ga, Hijab PKU Amanah, Stick Mozarella PKU, dan Shoes Homies yang cukup signifikan dari hari ke hari.

Peneliti ini menyarankan untuk kedepannya kepada masing-masing produk yang diteliti untuk mulai menggunakan trend baru di dalam dunia social media marketing Instagram yaitu mulai beralih ke akun bisnis, memaksimalkan iklan berbayar dari fitur facebook ads manager, mulai memperhatikan feed Instagram dari sisi informasi yang lengkap, foto yang berkualitas tinggi serta susunan yang rapi dan eye catching. Mulai mengupload postingan info edukasi yang sederhana untuk nantinya bisa menjadi konten yang shareable bagi followers. Merutinkan program charity/progam amal dan di upload di media sosial, sebab untuk menjalankan social media marketing tidak hanya sekedar berbicara menjual produk. Tidak lupa fitur ephemeral dalam Instagram juga harus dimaksimalkan untuk mendongkrak brand awareness kepada pelanggan. Aspek yang terpenting untuk menyentuh masyarakat umum dan melibatkan psikologis mereka adalah dengan mengkolaborasikan bisnis, teknologi, dan aksi sosial. Hal ini yang disebut dengan pendekatan socio-technopreneurship.

\section{REFERENSI}

Abdurrahman, M. S. (2015). Penerapan Inovasi Kewirausahaan Bagi Bisnis Komunikasi Pemula: Studi Kasus Strategi Bisnis di PT Edu Media Komunika. Jurnal Penelitian Komunikasi Dan Pembangunan, 16(1), 11-22.

https://doi.org/http://dx.doi.org/10.31346/jpikom.v16i1.1334

As'ad, Abu-Rumman, H., \& Alhadid, A. Y. (2014). The Impact of Social Media Marketing on Brand Equity: An Empirical Study on Mobile Service Providers in Jordan. Rev. Integr. Bus. Econ. Res, 3(1), 315-326.

Bayer, J. B., Ellison, N. B., Schoenebeck, S. Y., \& Falk, E. B. (2016). Sharing the small moments: ephemeral social interaction on Snapchat. Information, Communication \& Society, 19(7), 956-977.

Bungin, B. (2008). Penelitian Kualitatif. Kencana Prenada Media Group.

Chaedar, A. A. (2002). Pokoknya Kualitatif. Dasar-dasar Merancang dan Melakukan penelitian Kualitatif. Pustaka Jaya.

Constantinides, E. (2013). Social media marketing: Challenges and opportunities in the Web 2.0 marketplace. Consumer Information Systems and Relationship Management: Design, Implementation, and Use, 51-73. https://doi.org/10.4018/978-1-4666-40825.ch004 
Dewi, A. M. (2018). Pengaruh Iklan Online Melalui Instagram Terhadap Keputusan Pembelian Bagi Peningkatan Penjualan Produk Kuliner Lokal. Jurnal Ekonomi Universitas Kadika, 3(1).

Dewi, R. S. (2013). Pengaruh Faktor Modal Psikologis, Karakteristik Entrepreneur, Inovasi, Manajemen Sumber Daya Manusia, dan Karakteristik UKM Terhadap Perkembangan Usaha Pedagang di Pasar Tradisional (Studi kasus pada Pedagang Sembako dan Snack di Pasar Peterongan). Jurnal Administrasi Bisnis, 2(1), 29-40. https://doi.org/10.14710/jab.v2i1.5352

Diyatma, A., \& Irma, R. (2017). Pengaruh Promosi Melalui Media Sosial Instagram Terhadap Keputusan Pembelian Produk Saka Bistro \& bar. EProceedings of Management, 4(1).

Durianto, D. (2001). Strategi Menaklukan Pasar. Gramedia Pustaka Utama.

Gunelius, S. (2011). 30-Minute Social Media Marketing. McGraw-Hill Companies.

Guzmán, F., Abimbola, T., Tolba, A. H., \& Hassan, S. S. (2009). Linking customer-based brand equity with brand market performance: a managerial approach. Journal of Product \& Brand Management, 18(5), 356-366.

Hadiyati, E. (2011). Kreativitas dan Inovasi Berpengaruh Terhadap Kewirausahaan Usaha Kecil. Jurnal Manajemen Dan Kewirausahaan, 13(1), 8-16. https://doi.org/https://doi.org/10.9744/jmk.13.1.8-16

Handayani, D. (2010). The Official MIM Academy Coursebook Brand Operation. Esensi Erlangga Group.

Hanggono, A. A. (2015). Analisis atas praktek tam (technology acceptance model) dalam mendukung bisnis online dengan memanfaatkan jejaring sosial Instagram. Jurnal Administrasi Bisnis, 26(1).

Hasanah, L. L. N. El. (2015). Pengembangan Wirausaha Muda Ekonomi Kreatif Berbasis Budaya di Daerah Istimewa Yogyakarta. Jurnal Studi Pemuda, 4(2), 268-280.

Jussila, J. J., Kärkkäinen, H., \& Aramo-Immonen, H. (2014). Social media utilization in business-to-business relationships of technology industry firms. Computers in Human Behavior, 30, 606-613.

Koestoer, R. A., \& Roihan, I. (2016). Unpatented grashof-incubator as a part of communityenggagement in mechanical engineering university of Indonesia. Prosiding SENTRA (Seminar Teknologi Dan Rekayasa), 2, 285-287.

https://doi.org/https://doi.org/10.22219/sentra.v0i2.1767

Kotler, P., \& Keller, K. (2011). Marketing Management,14th Edition. Pearson.

Kumar, V., Bhaskaran, V., Mirchandani, R., \& Shah, M. (2013). Practice prize winnercreating a measurable social media marketing strategy: increasing the value and ROI of intangibles and tangibles for hokey pokey. Marketing Science, 32(2), 194-212.

Littlejohn, S. W., \& Karen, A. F. (2009). Teori Komunikasi (theories of human communication) (9th ed.). Salemba Humanika.

Lorenzo-Romero, C., Constantinides, E., \& Alarcón-del-Amo, M. D. C. (2013). Web aesthetics effects on user decisions: impact of exposure length on website quality perceptions and buying intentions. Journal of internet commerce, 12(1), 76-105. 
Müller-Lankenau, C., Wehmeyer, K., \& Klein, S. (2006). Strategic channel alignment: an analysis of the configuration of physical and virtual marketing channels. Information Systems and e-Business Management, 4(2), 187-216.

Moleong, L. J. (2007). Metodologi Penelitian Kualitatif (Revisi). Remaja Rosda Karya.

Morissan, M. A. (2010). Periklanan Komunikasi Pemasaran Terpadu. Kencana.

Najib, M. (2009). Analisis Konsumen Berpindah Merek ( BrandSwitcher) Pada Bank Syariah Dan Bank Konvensional. Islamic Finance \& Business Review, 4(1), 1-25. https://doi.org/http://dx.doi.org/10.30993/tifbr.v4i1.25

Nuraeni, S. D., \& Suryawardani, B. (2017). Analisis Efektivitas Promosi Melalui Media Sosial Instagram Pada Pt. Niion Indonesia Utama Tahun 2017. EProceedings of Applied Science, 3(2), 3(2).

Oktaviani, F., \& Rustandi, D. (2018). Implementasi Digital Marketing dalam Membangun Brand Awareness. PRofesi Humas, 3(1), 1-20.

Pride, W. M., Hughes, R. J., \& Kapoor, J. R. (2014). Foundations of business. Cengage Learning.

Putri, S. D. \& Fithrah, D. S. (2017). Pengaruh online marketing campaign \#samyangchallenge terhadap consumer behavior digital natives pengguna youtube Indonesia. Jurnal PRofesi Humas, 1(2), 132-141.

Rangkuti, F. (2003). The Power of Brands. Teknik Mengelola Brand Equity dan Strategi Pengembangan Merek. Jakarta. PT. Gramedia Pustaka Utama.

Rapp, A., Beitelspacher, L. S., Grewal, D., \& Hughes, D. E. (2013). Understanding social media effects across seller, retailer, and consumer interactions. Journal of the Academy of Marketing Science, 41(5), 547-566.

Riauan, M. A. I., \& Aziz, A. (2019). Professional Gamer: The Meaning on 'Point Blank Online'Play. Jurnal The Messenger, 11(1), 18-26.

Rosyadi, I. (2013). Strategi Pengembangan Usaha Mikro Milik Mahasiswa. Jurnal Manajemen Dan Bisnis, 17(UMKM), 112-122.

https://doi.org/https://doi.org/10.23917/benefit.v17i2.1385

Sahban, M. A. (2018). Kolaborasi Pembangunan Ekonomi di Negara Berkembang (1st ed.). SAH MEDIA.

Setiawan, H. (2017). Ekuitas Merek Dalam Aktivitas Showroom Event. Medium, 6(1), 3248.

Sudomo, S. (2013). Pengaruh Ekuitas Merek Terhadap Keputusan Pembelian (Studi Kasus Konsumen Pepsodent di Kabupaten Bantul). Jurnal Bisnis, Manajemen, Dan Akuntansi, 1(2), 33-48.

Sukur, E. (2012). Socio-Technopreneur. (Terhubung Berkala). http://mitimahasiswa.com/2012/09/13/sosioteknopreneur-ala-dr-edi-sukur/

Taprial, V., \& Kanwar, P. (2012). Understanding social media.

Tsimonis, G., \& Dimitriadis, S. (2014). Brand strategies in social media. Marketing Intelligence \& Planning.

Villaespesa, E., \& Wowkowych, S. (2020). Ephemeral Storytelling With Social Media: Snapchat and Instagram Stories at the Brooklyn Museum. Social Media+ Society, 6(1).

Yaghoobi, N. M., Salarzehi, Habibollah, Hedari, A. reza, \& Aramesh, H. (2010). An 
evaluation of independent entrepreneurship obstacles in industrial SMEs. European Journal of Social Sciences, 15(4), 512-520. 